Article

\title{
Chiral BINAP-based hierarchical porous polymers as platforms for efficient heterogeneous asymmetric catalysis
}

\author{
Tao Wang a,c, Yuan Lyu a,\#, Kai Xiong d, Wenlong Wang a , Hao Zhang e, Zhuangping Zhan d, \\ Zheng Jiang e, Yunjie Ding a,b,* \\ a Dalian National Laboratory for Clean Energy, Dalian Institute of Chemical Physics, Chinese Academy of Sciences, Dalian 116023, Liaoning, China \\ b State Key Laboratory of catalysis, Dalian Institute of Chemical Physics, Chinese Academy of Sciences, Dalian 116023, Liaoning, China \\ c University of Chinese Academy of Sciences, Beijing 100049, China \\ d Department of Chemistry, College of Chemistry and Chemical Engineering, Xiamen University, Xiamen 361005, Fujian, China \\ e Shanghai Synchrotron Radiation Facility, Shanghai Institute of Applied Physics, Chinese Academy of Sciences, Shanghai 201204, China
}

\section{A R T I C L E I N F O}

\section{Article history:}

Received 22 February 2017

Accepted 23 March 2017

Published 5 May 2017

\section{Keywords:}

(S)-4,4'-divinyl-BINAP

(S)-5,5'-divinyl-BINAP

Porous organic polymers supported

ruthenium

Heterogeneous asymmetric

hydrogenation

$\beta$-keto esters

\begin{abstract}
A B S T R A C T
Two vinyl-functionalized chiral 2,2'-bis(diphenylphosphino)-1,1'-binaphthyl (BINAP) ligands, $(S)$-4,4'-divinyl-BINAP and (S)-5,5'-divinyl-BINAP, were successfully synthesized. Chiral BINAP-based porous organic polymers (POPs), denoted as 4-BINAP@POPs and 5-BINAP@POPs, were efficiently prepared via the copolymerization of vinyl-functionalized BINAP with divinyl benzene under solvothermal conditions. Thorough characterization using nuclear magnetic resonance spectroscopy, thermogravimetric analysis, extended X-ray absorption fine structure analysis, and high-angle annular dark-field scanning transmission electron microscopy, we confirmed that chiral BINAP groups were successfully incorporated into the structure of the materials considered to contain hierarchical pores. Ru was introduced as a catalytic species into the POPs using different synthetic routes. Systematic investigation of the resultant chiral Ru/POP catalysts for heterogeneous asymmetric hydrogenation of $\beta$-keto esters revealed their excellent chiral inducibility as well as high activity and stability. Our work thereby paves a path towards the use of advanced hierarchical porous polymers as solid chiral platforms for heterogeneous asymmetric catalysis.
\end{abstract}

(C) 2017, Dalian Institute of Chemical Physics, Chinese Academy of Sciences. Published by Elsevier B.V. All rights reserved.

\section{Introduction}

Recently, porous organic materials, including porous organic polymers (POPs), metal-organic frameworks (MOFs), and covalent organic frameworks (COFs) have emerged as versatile platforms for the deployment of catalysts because of their porous nature and high surface area [1-7]. However, MOFs and COFs are unstable under many circumstances such as in acidic, basic, and moist environments because of the connection of the coordination bonds in MOFs and the presence of imine or boronate ester groups in COFs, which severely limits their applications in catalysis [8,9]. In contrast, POPs are advantageous compared with MOFs and COFs in terms of hydrothermal stability and chemical robustness because of the stronger linkage of their versatile covalent bonds apart from imines and boronate esters [10-14]. Thus, POPs can be designed as an ideal platform for incorporating molecular catalytic modules into highly stable and recyclable heterogeneous catalytic systems by

\footnotetext{
* Corresponding author. Tel/Fax: +86-411-84379143; E-mail: dyj@dicp.ac.cn

\# Corresponding author. Tel: +86-411-84379601; Fax: +86-411-84379143; E-mail: luyuan@dicp.ac.cn

This work was supported by the Strategic Priority Research Program of the Chinese Academy of Sciences (XDB17020400).

DOI: 10.1016/S1872-2067(17)62826-2 | http://www.sciencedirect.com/science/journal/18722067 | Chin. J. Catal., Vol. 38, No. 5, May 2017
} 
taking advantage of their permanent porosity and the ability to tune their compositions and properties at the molecular level [15-17].

Compared with the large number of reported POPs, chiral POPs remain scarce. Lin et al. [18] developed the synthesis process for binaphthol-ligated, Ti-incorporating porous cross-linked polymers for catalytic asymmetric diethylzinc addition to aldehydes. Wang and co-workers [19] described the construction of a $\alpha, \alpha, \alpha^{\prime}, \alpha^{\prime}$-tetraaryl-1,3-dioxolane-4,5-dimethanol (TADDOL)-embedded chiral POP catalyst and its structure-activity relationship. In addition, to date, most research has been focused on microporous chiral POPs [18,20-22]; studies aimed at the syntheses of advanced hierarchical (in combination with micropores and mesopores) chiral POPs are even more scarce [23,24]. Abundant micropores generally favour a high density of catalytically active sites distributed in the catalyst particles, whereas mesopores improve the mass transfer efficiency to enable free contact of the substrate with catalytically active sites in heterogeneous catalysis [25-28]. Therefore, the synthesis of hierarchical chiral POPs is of great interest. The $C_{2}$-symmetric BINAP (2,2'-bis(diphenylphosphino)1,1'-binaphthyl) ligand, which was reported by Noyori et al. [29] in 1980, represents one of the most efficient ligands. BINAP and its derivatives have been widely used in asymmetric catalysis and extensively investigated, especially in asymmetric hydrogenation. The heterogenization of BINAP has been a long-term research area in heterogeneous asymmetric catalysis [30-38]. Using the BINAP ligand, Xiao et al. [23] synthesized a vinyl-modified BINAP dioxide through the steps of oxidation, nitration, reduction, and acylation, which was denoted as 5,5'-diacryloylamino BINAP dioxide. After copolymerization with divinyl benzene (DVB) and reduction with $\mathrm{HSiCl}_{3}$, porous cross-linked polymers (PCPs) with BINAP (PCP-BINAP) were obtained. The prepared heterogeneous catalyst $\mathrm{Ru} / \mathrm{PCP}-\mathrm{BINAP}$ exhibited high activity and recyclability in the asymmetric hydrogenation of $\beta$-keto esters. Inspired by this creative work, we recently reported excellent asymmetric hydroformylation catalysts through radical polymerization of $(S)-5,5^{\prime}$-divinyl-BINAP and a series of comonomers.

Herein, we report the construction of two advanced hierarchical chiral POPs, which were based on two synthesized vinyl-functionalized chiral BINAP ligands, $(S)$-4,4'-divinyl-BINAP and (S)-5,5'-divinyl-BINAP. The chiral BINAP-based POPs, which were denoted as 4-BINAP@POPs and 5-BINAP@POPs, were efficiently prepared via the copolymerization of vinyl-functionalized BINAP with DVB under solvothermal conditions. After exploring different synthetic routes and impregnating the POPs with a series of Ru species, the resultant materials were systematically studied for the heterogeneous asymmetric hydrogenation of $\beta$-keto esters.

\section{Experimental}

\subsection{Materials}

All the solvents were analytical grade and were purified by distillation under Ar atmosphere before use. Unless otherwise noted, all the manipulations were performed under an Ar atmosphere either in a glove box or using standard Schlenk techniques. DVB (80\%) was provided by J\&K Chemical as a mixture of 1,2-, 1,3-, and 1,4-DVB.

\subsection{Ligand Synthesis}

The synthesis routes of $(S)-5,5^{\prime}$-divinyl-BINAP have been previously reported. Here, we describe the synthesis routes of (S)-4,4'-divinyl-BINAP in Scheme 1.

Compound 1, $(S)$-BINAP dioxide: $(S)$-BINAP (3 mmol, 1.87 g) was dissolved in dichloromethane (DCM, $60 \mathrm{~mL}$ ) followed by the dropwise addition of $\mathrm{H}_{2} \mathrm{O}_{2}(18.32 \mathrm{mmol}, 6.06 \mathrm{~mL})$. The reaction was monitored by thin-layer chromatography (TLC). After being stirred for $30 \mathrm{~min}$ at room temperature, the solution was extracted with water $(30 \mathrm{~mL})$. The organic phase was washed with $10 \% \mathrm{NaHSO}_{3}$ aqueous solution ( $50 \mathrm{~mL}$ ) and dried over $\mathrm{Na}_{2} \mathrm{SO}_{4}$. The solvent was removed under vacuum, and 1.95 $\mathrm{g}$ of a white solid ( $99 \%$ yield) was obtained, which was denoted as $(S)$-BINAPO.

Compound 2, (S)-4,4'-diBr-BINAPO: (S)-BINAPO (10 mmol, $6.55 \mathrm{~g})$ was dissolved in DCM $(150 \mathrm{~mL})$ followed by the addition of liquid bromine $(30 \mathrm{mmol}, 4.8 \mathrm{~g}$ ) and pyridine $(10 \mathrm{mmol}$, $0.79 \mathrm{~g}$ ). After being stirred for $24 \mathrm{~h}$ at room temperature, the solution was washed with $10 \% \mathrm{NaHSO}_{3}$ aqueous solution, saturated brines, and saturated sodium bicarbonate aqueous solution, dried over $\mathrm{Na}_{2} \mathrm{SO}_{4}$, and evaporated under vacuum to remove the solvent. After repeating the above steps twice, $6.10 \mathrm{~g}$ of a white solid (75\% yield) was obtained, which was denoted as $(S)-4,4^{\prime}$-diBr-BINAPO.

Compound 3, (S)-4,4'-divinyl-BINAPO: $(S)$-4,4'-diBr-BINAPO $(1.0 \mathrm{mmol}, 0.82 \mathrm{~g}$ ), potassium vinyltrifluoroborate $(2.4 \mathrm{mmol}$, $0.32 \mathrm{~g})$ and $\mathrm{PdCl}_{2}(\mathrm{dppf}) \mathrm{CH}_{2} \mathrm{Cl}_{2}(0.08 \mathrm{mmol}, 0.058 \mathrm{~g})$ were placed in a three-necked flask. $N$-propanol $(n-\mathrm{PrOH}, 10 \mathrm{~mL})$ and triethylamine $(2.0 \mathrm{mmol}, 0.20 \mathrm{~g})$ were added to the flask. The reaction was monitored by TLC. After being refluxed for $3 \mathrm{~h}$, the solvent was removed under vacuum. The precipitate was passed through a silica gel column and dried under vacuum to produce $0.565 \mathrm{~g}$ of a white solid (80\% yield), which was denoted as (S)-4,4'-divinyl-BINAPO.

Compound 4, (S)-4,4'-divinyl-BINAP: $(S)$-4,4'-divinylBINAPO (1.0 mmol, $0.70 \mathrm{~g}$ ), trichlorosilane (3.0 mmol, $0.41 \mathrm{~g}$ )
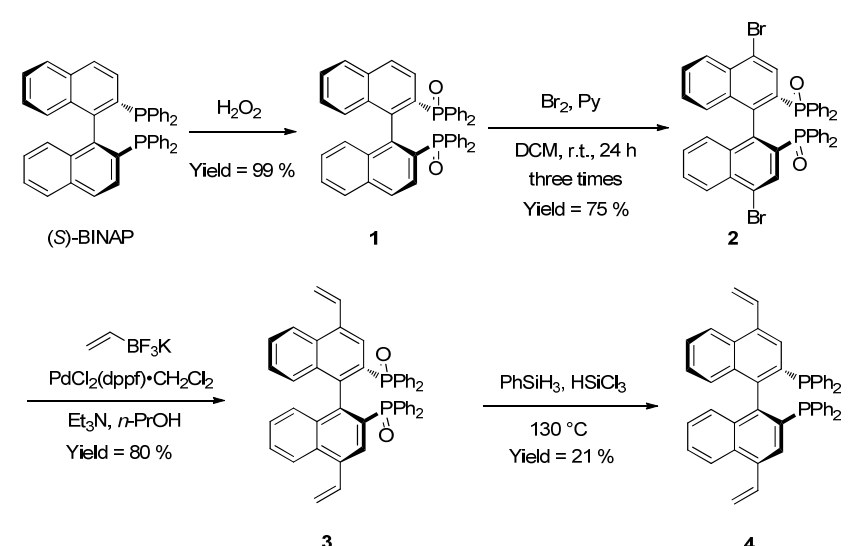

Scheme 1. Synthesis of (S)-4,4'-divinyl-BINAP. 
and phenylsilane $(3.0 \mathrm{mmol}, 0.32 \mathrm{~g})$ were placed in a three-necked flask with the addition of toluene $(10 \mathrm{~mL})$. The reaction was monitored by TLC. After being refluxed for $3 \mathrm{~h}$, the solvent was cooled to $0{ }^{\circ} \mathrm{C}$, followed by the slow addition of $\mathrm{NaOH}$ aqueous solution. Then, the solution was extracted with water and dried over $\mathrm{Na}_{2} \mathrm{SO}_{4}$. The solvent was removed under vacuum. The precipitate was passed through a silica gel column and dried under vacuum to produce $0.15 \mathrm{~g}$ of a white solid (21\% yield), which was denoted as $(S)$-4,4'-divinyl-BINAP. ${ }^{1} \mathrm{H}$ NMR (400 MHz, $\left.\mathrm{CDCl}_{3}\right) \delta 5.38(\mathrm{~d}, 1 \mathrm{H}, J=10.9 \mathrm{~Hz}), 5.52(\mathrm{~d}, 1 \mathrm{H}, J$ $=17.1 \mathrm{~Hz}), 6.85-6.96(\mathrm{~m}, 2 \mathrm{H}), 7.00-7.20(\mathrm{~m}, 10 \mathrm{H}), 7.34-7.41$ (m, 1H), 7.42-7.49 (m, 1H), 7.55-7.63 (s, 1H), $8.09(\mathrm{~d}, 1 \mathrm{H}, J=$ $8.5 \mathrm{~Hz}) ;{ }^{31} \mathrm{P} \mathrm{NMR}\left(161 \mathrm{MHz}, \mathrm{CDCl}_{3}\right)-14.9 \mathrm{~Hz}$.

\subsection{Synthesis of BINAP@POPs}

The synthesis of the BINAP@POPs and catalysts is summarized in Scheme 2. In an autoclave, $0.1 \mathrm{~g}(S)$-4,4'-divinyl-BINAP and $1.0 \mathrm{~g}$ DVB were dissolved in $10 \mathrm{~mL}$ of tetrahydrofuran (THF), followed by the addition of $25 \mathrm{mg}$ of 2,2'-azoisobutyronitrile (AIBN). The mixture was first stirred for $10 \mathrm{~min}$ at room temperature and then heated at $100{ }^{\circ} \mathrm{C}$ for $24 \mathrm{~h}$. The solvent was removed under vacuum at $65^{\circ} \mathrm{C}$, and a white solid was obtained, which was denoted as 4-BINAP@POPs.

Using $\quad 0.1 \mathrm{~g}$ of $(S)-5,5^{\prime}$-divinyl-BINAP instead of $(S)-4,4^{\prime}$-divinyl-BINAP in the solution above, 5-BINAP@POPs

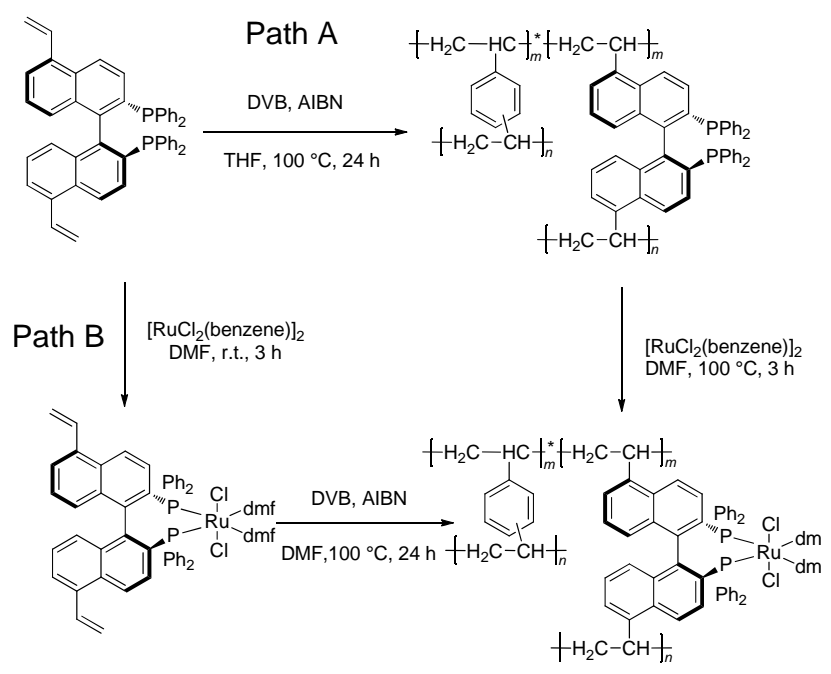

Ru/5-BINAP@POPs-1 and Ru/5-BINAP@POPs-2

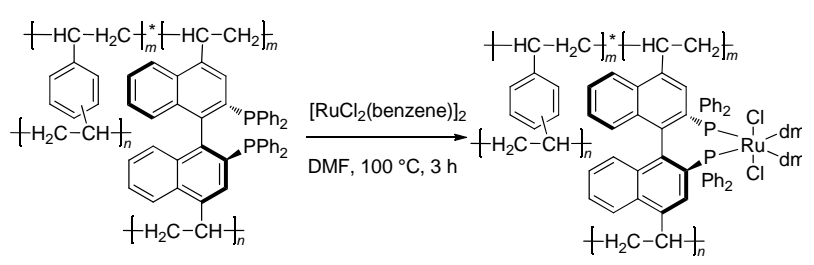

Scheme 2. Synthesis of 4-BINAP@POPs, 5-BINAP@POPs, and its supported Ru complexes. were obtained via the same synthesis method.

\subsection{Preparation of polymer-supported catalysts}

First, $0.41 \mathrm{~g}$ 4-BINAP@POPs and 0.0069g $\mathrm{g}$ Ru(benzene) $\left.\mathrm{Cl}_{2}\right]_{2}$ $(0.028 \mathrm{mmol} \mathrm{Ru})$ were added to $6 \mathrm{~mL}$ of $\mathrm{N}, \mathrm{N}$ - dimethylformamide (DMF). After being refluxed for $3 \mathrm{~h}$ at $100{ }^{\circ} \mathrm{C}$, the solvent was removed under vacuum at $65{ }^{\circ} \mathrm{C}$, and a dark-green solid was obtained, which was denoted as Ru/4-BINAP@POPs.

Using $0.41 \mathrm{~g}$ of 5-BINAP@POPs instead of 4-BINAP@POPs in the solution above, Ru/5-BINAP@POPs-1 were obtained via the same strategies.

As shown in path B of Scheme 2, the ligand $(S)-5,5$ '-divinyl-BINAP was coordinated with $\left[\mathrm{Ru}(\right.$ benzene $\left.) \mathrm{Cl}_{2}\right]$ and then copolymerized with DVB to obtain the catalyst Ru/5-BINAP@POPs-2. First, 0.1 g (S)-5,5'-divinyl-BINAP and $0.0186 \mathrm{~g}$ [Ru(benzene $\left.) \mathrm{Cl}_{2}\right]_{2}(0.074 \mathrm{mmol} \mathrm{Ru})$ were dissolved in $4 \mathrm{~mL}$ of DMF, and the mixture was stirred for $3 \mathrm{~h}$ at room temperature. Then, $1.0 \mathrm{~g}$ DVB, $0.025 \mathrm{~g}$ AIBN, and $6 \mathrm{~mL}$ of DMF were added to the mixture. The mixture was first stirred for $10 \mathrm{~min}$ at room temperature and then heated at $100^{\circ} \mathrm{C}$ for $24 \mathrm{~h}$. The solvent was removed, and a dark-green solid was obtained, which was denoted as Ru/5-BINAP@POPs-2.

First, 0.35 g 5-BINAP@POPs and 0.0072 g [Ru(p-cyme) $\left.\mathrm{Cl}_{2}\right]_{2}$ $(0.024 \mathrm{mmol} \mathrm{Ru})$ were added to $5 \mathrm{~mL}$ of DMF. After being refluxed for $3 \mathrm{~h}$ at $100{ }^{\circ} \mathrm{C}$, the solvent was removed and a dark-green solid was obtained, which was denoted as Ru/5-BINAP@POPs-3.

First, 0.27 g 5-BINAP@POPs and $0.0050 \mathrm{~g} \mathrm{RuCl}_{3} \cdot x \mathrm{H}_{2} \mathrm{O}(0.018$ $\mathrm{mmol} \mathrm{Ru}$ ) were added to $5 \mathrm{~mL}$ of DMF. After being refluxed for $3 \mathrm{~h}$ at $100^{\circ} \mathrm{C}$, the solvent was removed and a dark-green solid was obtained, which was denoted as Ru/5-BINAP@POPs-3.

\subsection{Characterization}

The liquid-state NMR spectra were recorded on a $400-\mathrm{MHz}$ spectrometer. The chemical shifts are reported in ppm. The $1 \mathrm{H}$ NMR spectra were referenced to $\mathrm{CDCl}_{3}(0 \mathrm{ppm})$, and the ${ }^{13} \mathrm{C}$ NMR spectra were referenced to $\mathrm{CDCl}_{3}(77.0 \mathrm{ppm})$. All the ${ }^{13} \mathrm{C}$ NMR spectra were measured with complete proton decoupling. The signal patterns were indicated as s, singlet; $d$, doublet; $t$, triplet; q, quartet; $\mathrm{m}$, multiplet; br, broad singlet; and $J$, coupling constant in Hz. The solid-state NMR spectra were obtained using a Varian Infinity-Plus 400 spectrometer. The ${ }^{31 P}$ MAS NMR spectra were recorded with a $5-\mathrm{mm}$ probe at a frequency of $161.8 \mathrm{MHz}$ under a magic angle spinning rate of $10 \mathrm{kHz}$ and a delay of $4 \mathrm{~s}$. The chemical shifts were referenced to $85 \% \mathrm{H}_{3} \mathrm{PO}_{4}$. The ${ }^{13} \mathrm{C} \mathrm{CP} / \mathrm{MAS}$ NMR spectra were recorded under a magic angle spinning rate of $6 \mathrm{kHz}$. Nitrogen isotherms at $77.3 \mathrm{~K}$ were measured using a Quantachrome Autosorb-1. Thermogravimetric analysis (TGA) was performed using a NETZSCH STA $449 \mathrm{~F} 3$, and the samples were heated from 40 to $1000{ }^{\circ} \mathrm{C}$ at a rate of $10{ }^{\circ} \mathrm{C} / \mathrm{min}$ under air. Inductively coupled plasma atomic emission spectroscopy (ICP-AES) analysis of the liquid samples was performed on a Perkin-Elmer 7300DV. High-angle annular dark-field scanning transmission electron microscopy (HAADF STEM) images were obtained using a JEM-ARM200F. The 
K-edge extended X-ray absorption fine structure spectra (EXAFS) of Ru were obtained at the BL14W1 beamline of SSRF, SINAP (Shanghai, China) using a Si(311) crystal monochromator. The storage ring was operated at $3.5 \mathrm{GeV}$ with injection currents of $200 \mathrm{~mA}$. The data were recorded in the fluorescence mode. The EXAFS data were analysed using the Demeter software package. Fourier transformation of the EXAFS data was applied to the $\mathrm{k}^{3}$-weighted functions. The theoretical scattering amplitude and phase-shift functions of all the paths for fitting the EXAFS data were calculated using the FEFF6 code.

\subsection{Catalytic process}

As a typical run for asymmetric hydrogenation of $\beta$-keto esters, $0.026 \mathrm{~g} \mathrm{Ru}$ /5-BINAP@POPs-1 catalyst, $0.20 \mathrm{~g}$ methyl acetoacetate, and $2 \mathrm{~mL}$ of isopropanol (ipro) were added to a 30-mL autoclave in a glove box. After the reactor was purged with $\mathrm{H}_{2}$ four times, its pressure was finally adjusted to the desired value, heated from room temperature to the reaction temperature of $50{ }^{\circ} \mathrm{C}$, and stirred for $10 \mathrm{~h}$. The catalyst was separated by centrifugation, and the product was analysed using gas chromatography (GC; Agilent 7890B gas chromatograph equipped with a flame ionization detector and a Cyclosil-B capillary column).

For recycling the catalyst, $0.052 \mathrm{~g} \mathrm{Ru} / 5$-BINAP@POPs-1 catalyst, $0.40 \mathrm{~g}$ methyl acetoacetate, and $4 \mathrm{~mL}$ of ipro were used. The catalyst was separated by centrifugation (performed in a glove box $)$, washed with ipro $(3 \times 2 \mathrm{~mL})$; the catalyst was then used directly for the next catalytic reaction.

\section{Results and discussion}

\subsection{Characterization}

The pore properties of the three catalysts were analysed using $\mathrm{N}_{2}$ physisorption isotherms (Fig. 1(a)). The catalysts were insoluble and porous with large surface areas of $1058-1070 \mathrm{~m}^{2} / \mathrm{g}\left(A_{\mathrm{BET}}\right)$ and pore volumes of $1.19-1.64 \mathrm{~cm}^{3} / \mathrm{g}$. The Ru/5-BINAP@POPs-2 contained larger mesopores than the Ru/4-BINAP@POPs and Ru/5-BINAP@POPs-1. Meanwhile, the polymers of 4-BINAP@POPs and 5-BINAP@POPs had surface areas greater than $1600 \mathrm{~m}^{2} / \mathrm{g}$. The high $\mathrm{P} / \mathrm{Ru}$ molar ratio $(\mathrm{P} / \mathrm{Ru}=2)$ can explain the different pore properties of the polymers and catalysts. Notably, polyDVB, which is obtained by the self-polymerization of DVB, only gives a $A$ BET of $816 \mathrm{~m}^{2} / \mathrm{g}$. These results demonstrate that the addition of the rigid and sterically chiral divinyl-BINAP ligand is beneficial for increasing the surface areas and pore volumes of polymers. The three catalysts all contained micropores and mesopores, as further confirmed by the pore size distribution curves calculated using density functional theory (DFT; Fig. 1(b)).

The ${ }^{13} \mathrm{C}$ MAS NMR spectra of 4-BINAP@POPs and 5-BINAP@POPs both contained clear resonance peaks at 145, 137 , and $128 \mathrm{ppm}$, which were assigned to the carbon of naph-
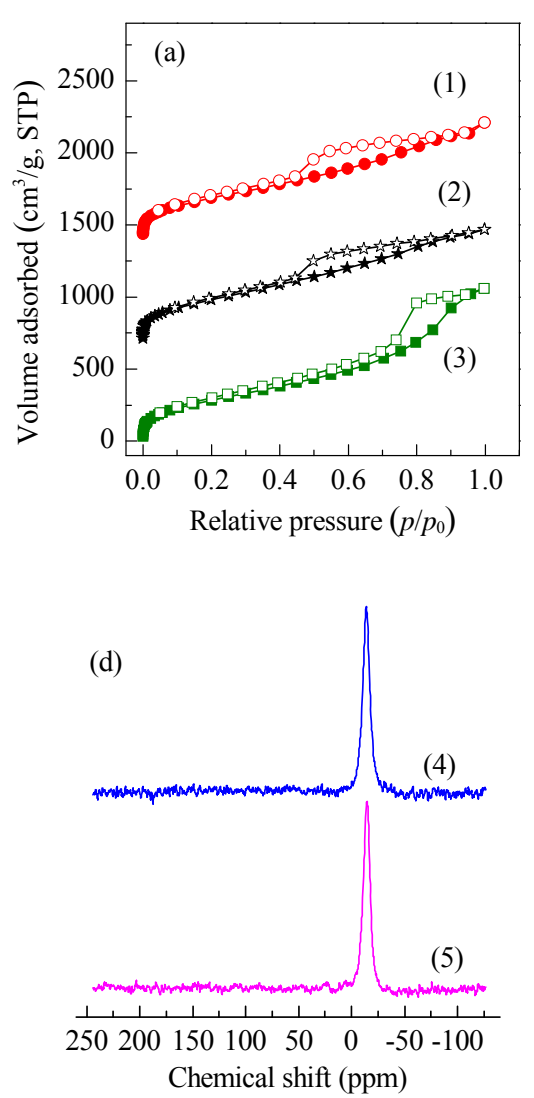
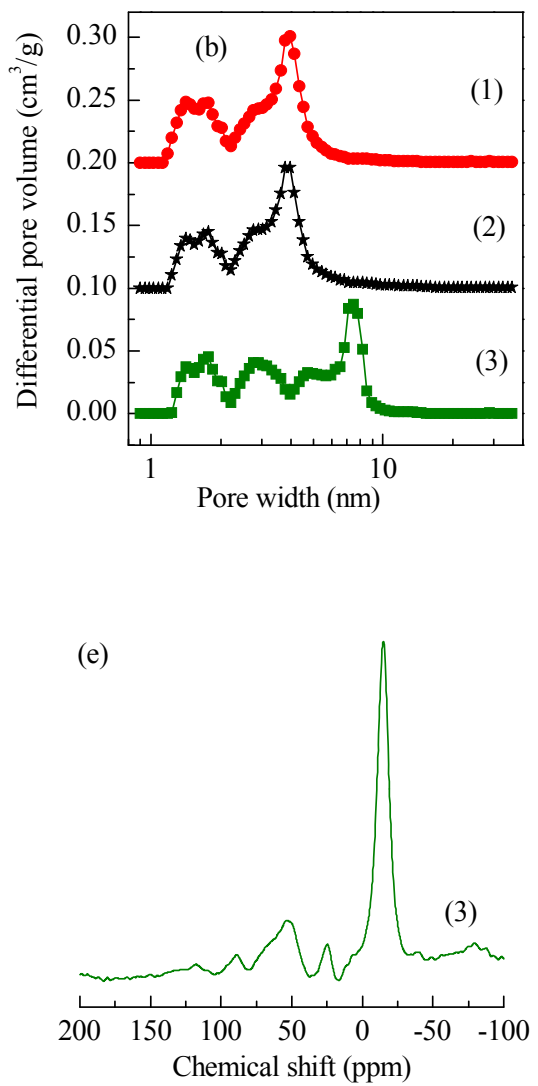
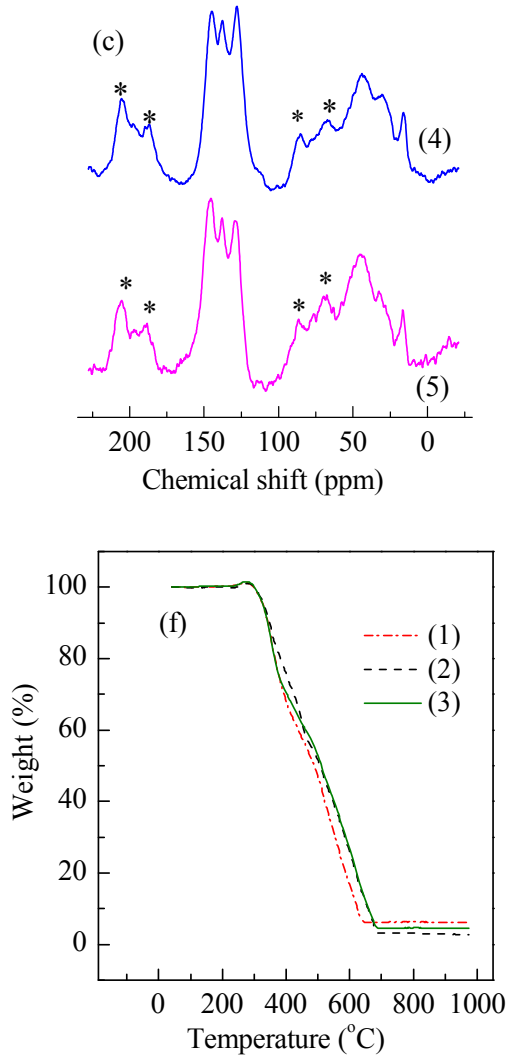

Fig. 1. $\mathrm{N}_{2}$ isotherms (a), pore size distribution calculated by DFT (b), ${ }^{13} \mathrm{C}$ CP/MAS NMR spectra (c), ${ }^{31 P}$ MAS NMR spectra (d), ${ }^{31} \mathrm{P}$ MAS NMR spectra (e), and TG curves (f) of Ru/4-BINAP@POPs (1), Ru/5-BINAP@POPs-1 (2), Ru/5-BINAP@POPs-2 (3), 4-BINAP@POPs (4), and 5-BINAP@POPs (5). 
thalene and benzene rings of the BINAP ligand and DVB (Fig. 1(c)). The resonance peaks near $44.0 \mathrm{ppm}$ with relatively large peak areas are mainly attributed to the carbon in the alkyl linker formed by the copolymerization of vinyl functional groups. Notably, the spectra show small peaks at 114 ppm corresponding to vinyl groups, indicating the high degree of the copolymerization of the ligands and DVB. The ${ }^{31} \mathrm{P}$ MAS NMR spectrum of 4-BINAP@POPs produced a signal at $-14.0 \mathrm{ppm}$ and that of 5-BINAP@POPs produced a signal at -14.6 ppm (Fig. 1(d)). No other obvious signals are observed for either polymer, which indicates that the phosphine in the polymer backbone is not oxidized. The 31P MAS NMR spectrum of Ru/5-BINAP@POPs-2, a representative catalyst, exhibited a broad peak at $52.8 \mathrm{ppm}$, which could be assigned to the unprotected phosphine coordinated with Ru species (Fig. 1(e)). In addition, the relatively less intensive peak at $24.9 \mathrm{ppm}$ was attributed to phosphorus of phosphine oxide.

Excellent thermal stability is a crucial requirement for polymer-supported catalysts. The TGA curves under air demonstrate that the catalysts exhibited excellent thermal stability without any decomposition at $300^{\circ} \mathrm{C}$ (Fig. 1(f)).

To confirm the state of the Ru species in our heterogeneous catalyst, EXAFS and HAADF-STEM characterization were employed for the fresh and used Ru/5-BINAP@POPs-1 catalyst. As observed in Fig. 2 and Table 1, no obvious Ru-Ru bonds were detected regardless of whether the sample was fresh or used,

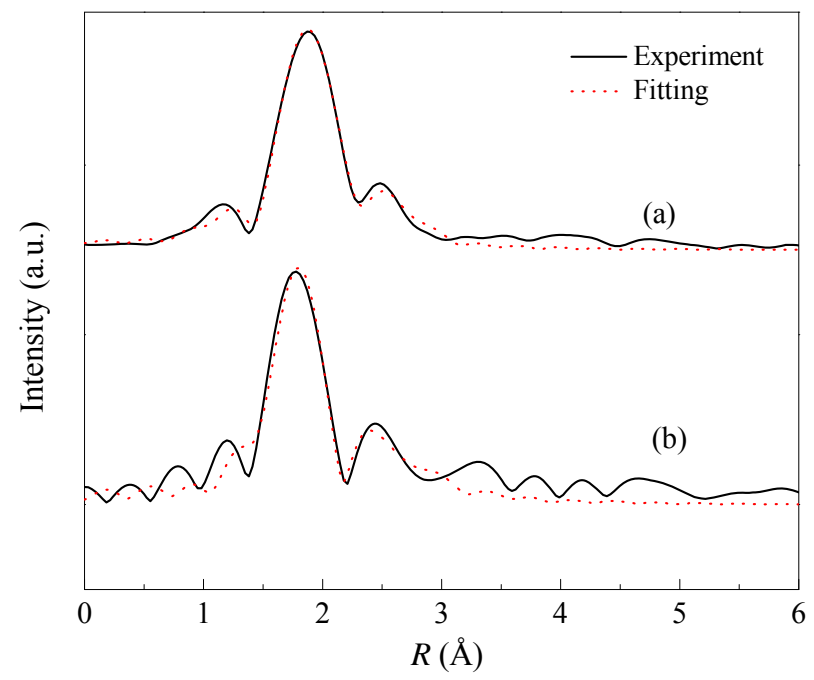

Fig. 2. Ru K-edge $\mathrm{k}^{3}$-weighted Fourier-transform EXAFS spectra of fresh (a) and used (b) (recycled 6 times) Ru/5-BINAP@POPs-1 catalyst.

Table 1

Curve-fitting analysis of the EXAFS traces.

\begin{tabular}{lccccc}
\hline Sample & Shell & $N$ & $R(\AA)$ & $\sigma^{2} \times 103\left(\AA^{2}\right)$ & $\begin{array}{c}R \\
\text { factor }\end{array}$ \\
\hline Ru/5-BINAP@ & $\mathrm{Ru}-\mathrm{P}$ & 2.0 & $2.26( \pm 0.04)$ & $2.5( \pm 1.0)$ & 0.006 \\
POPs-1 (fresh) & $\mathrm{Ru}-\mathrm{Cl}$ & 2.0 & $2.40( \pm 0.02)$ & $3.0( \pm 1.0)$ & \\
& $\mathrm{Ru}-0$ & 2.0 & $1.90( \pm 0.02)$ & $11.4( \pm 7.0)$ & \\
Ru/5-BINAP@ & $\mathrm{Ru}-\mathrm{P}$ & 2.0 & $2.22( \pm 0.06)$ & $14.7( \pm 10.0)$ & 0.012 \\
POPs-1 (used) & $\mathrm{Ru}-\mathrm{Cl}$ & 2.0 & $2.34( \pm 0.02)$ & $8.4( \pm 3.5)$ & \\
& $\mathrm{Ru}-0$ & 2.0 & $2.13( \pm 0.04)$ & $1.3( \pm 2.0)$ & \\
\hline
\end{tabular}

$N$, coordination number; $R$, distance between absorber and backscattered atom; $\sigma^{2}$, Debye-Waller factor.
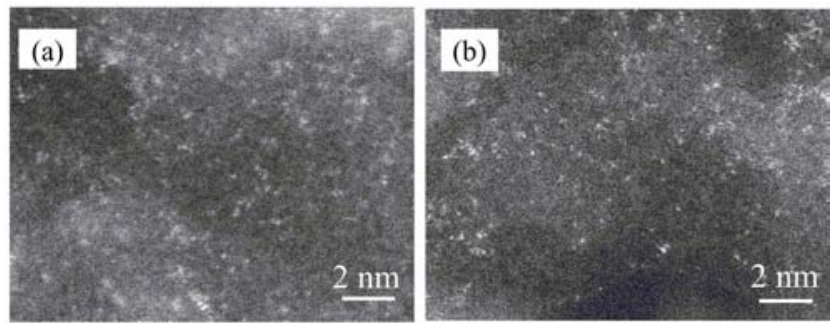

Fig. 3. HAADF-STEM images of fresh (a) and used (b) (recycled 6 times) Ru/5-BINAP@POPs-1 catalyst.

indicating that Ru species are dispersed as a single atom on the 5-BINAP@POPs, which was further confirmed by the HAADF-STEM images (Fig. 3). In addition, $\mathrm{P}, \mathrm{Cl}$, and $\mathrm{O}$ were coordinated with $\mathrm{Ru}$, whose coordination numbers are all two [40-42]. Moreover, considering the uncertainty of the fitting results, we believe that the bond lengths of $\mathrm{Ru}-\mathrm{P}$ and $\mathrm{Ru}-\mathrm{Cl}$ in the fresh and used samples were the same because they are all from the same ligands. The $\mathrm{Ru}-\mathrm{O}$ bond lengths of the fresh and used Ru/5-BINAP@POPs-1 sample were 1.90 and $2.13 \AA$, respectively. The distinct bond length of $\mathrm{Ru}-\mathrm{O}$ is due to the difference between DMF and ipro. The Ru species in the fresh sample was coordinated with the 0 atom of DMF. Ipro was selected as the reaction solvent for the asymmetric hydrogenation of the -keto ester. Therefore, the Ru species in the used sample was coordinated with the $\mathrm{O}$ atom of ipro.

\subsection{Catalytic tests}

\subsubsection{Reaction rate of $R u / 4-B I N A P @ P O P s$ and Ru/5-BINAP@POPs-1}

The effect of the catalysts for the hydrogenation of methyl acetoacetate on the reaction rate and enantioselectivity was studied using Ru/4-BINAP@POPs and Ru/5-BINAP@POPs-1 (Fig. 4). Ru/5-BINAP@POPs-1 produced a 74.3\% yield and 89.1\% enantiomeric excess (ee) within $1 \mathrm{~h}$, whereas $\mathrm{Ru}$ /4-BINAP@POPs only produced a 29.1\% yield and 84.6\% ee.

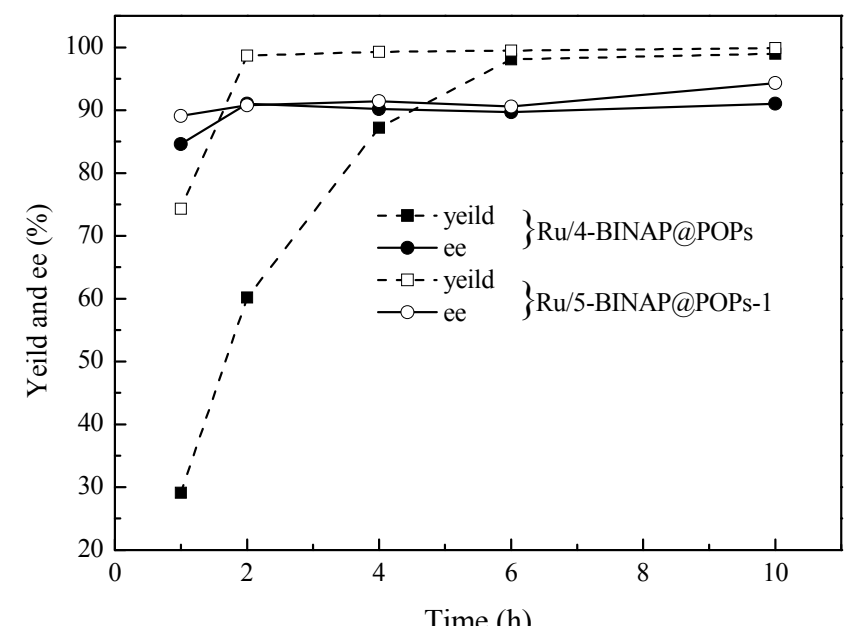

Fig. 4. Effect of Ru/4-BINAP@POPs and Ru/5-BINAP@POPs-1 on the reaction rate and enantioselectivity. Reaction conditions: methyl acetoacetate $(1.72 \mathrm{mmol})$, catalyst $(0.00172 \mathrm{mmol} \mathrm{Ru})$, ipro $(2 \mathrm{~mL})$, initial $\mathrm{H}_{2}$ pressure $(4 \mathrm{MPa}), 50^{\circ} \mathrm{C}, 10 \mathrm{~h}$, and the yield and ee values were determined by GC on a Cyclosil-B capillary column. 
After 6 h, the yield was more than $98 \%$ for both catalytic systems. In particular, Ru/5-BINAP@POPs-1 produced a 99.5\% yield and 94.3\% ee after 10 h. Ru/5-BINAP@POPs-1 exhibited a higher reaction rate and similar enantioselectivity compared with Ru/4-BINAP@POPs. Considering the similarity in the pore structures of the two catalysts, the divinyl derivatives of BINAP, which were substituted in different positions, affected the chiral characters of the BINAP ligand in the polymer backbone and may ultimately affect their catalytic performance. The bulky building blocks formed in the 4,4'-positions were closer to the phosphorus atoms of BINAP than the 5,5'-positions, which made the catalyst of Ru/4-BINAP@POPs not easily accessible to the substrate.

\subsubsection{Catalytic activities of different 5-BINAP@POP-supported catalysts}

The catalytic performance of different 5-BINAP@POP-supported catalysts was also studied (Table 2). As previously mentioned, Ru/5-BINAP@POPs-1 and $\mathrm{Ru} / 5-B I N A P @ P O P s-2$ were synthesized via different strategies (post-synthesis and one-pot, respectively), leading to distinct effects on the catalytic activity. The catalyst prepared through post-synthesis (Table 2, entry 1 ) exhibited better activity and enantioselectivity than the one-pot sample (Table 2, entry 2). This finding may be attributed to part of the Ru species being embedded in the framework of the Ru/5-BINAP@POPs-2 catalyst, which therefore restricted the accessibility of the reagent to the active sites of the catalyst [39]. Ru/5-BINAP@POPs-3 and Ru/5-BINAP@POPs-4 were obtained using the post-synthesis strategy using the $\mathrm{Ru}$ precursors of $\left[\mathrm{Ru}(\mathrm{p} \text {-cyme }) \mathrm{Cl}_{2}\right]_{2}$ and $\mathrm{RuCl}_{3} \cdot \mathrm{H}_{2} \mathrm{O}$, respectively. The activity and enantioselectivity of the catalysts decreased in the order Ru/5-BINAP@POPs-1 > Ru/5-BINAP@POPs-3 > Ru/5-BINAP@ OPs-4. Therefore, the catalyst that was post-synthesized by the 5-BINAP@POPs polymer and [Ru(benzene) $\left.\mathrm{Cl}_{2}\right]_{2}$ precursor were selected for further study.

\subsubsection{Optimization of reaction conditions}

The effects of various parameters (solvent, reaction temperature, and $\mathrm{H}_{2}$ pressure) on the product yield and enantioselectivity were investigated (Table 3). The insoluble catalyst was well swollen by a wide range of organic solvents. Alcoholic sol-

\section{Table 2}

Different 5-BINAP@POP-supported catalysts for hydrogenation reaction.

\begin{tabular}{|c|c|c|c|}
\hline Entry & Catalyst ${ }^{a}$ & Yield $^{\mathrm{b}}(\%)$ & $\mathrm{ee}^{\mathrm{b}}(\%)$ \\
\hline 1 & Ru/5-BINAP@POPs-1 & $>99.5$ & 94.3 \\
\hline 2 & Ru/5-BINAP@POPs-2 & 79.9 & 85.8 \\
\hline 3 & Ru/5-BINAP@POPs-3 & 97.3 & 91.7 \\
\hline 4 & Ru/5-BINAP@POPs-4 & 87.2 & 86.1 \\
\hline
\end{tabular}

a Reaction conditions: methyl acetoacetate $(1.72 \mathrm{mmol})$, catalyst (0.00172 mmol Ru), ipro (2 mL), initial $\mathrm{H}_{2}$ pressure (4 MPa), $50{ }^{\circ} \mathrm{C}, 10$ h.

${ }^{\mathrm{b}}$ Determined by GC on a Cyclosil-B capillary column.
Table 3

Optimization of hydrogenation reaction parameters.

\begin{tabular}{|c|c|c|c|c|c|}
\hline Entry & Solvent ${ }^{\mathrm{a}}$ & Temp. $\left({ }^{\circ} \mathrm{C}\right)$ & $p_{\mathrm{H}_{2}}(\mathrm{MPa})$ & Yield b (\%) & $\mathrm{ee}^{\mathrm{b}}(\%)$ \\
\hline 1 & THF & 50 & 4 & $>99.5$ & 84.1 \\
\hline 2 & $\mathrm{PhH}$ & 50 & 4 & 64.1 & 72.9 \\
\hline 3 & $\mathrm{PhMe}$ & 50 & 4 & $>99.5$ & 68.9 \\
\hline 4 & $\mathrm{MeOH}$ & 50 & 4 & $>99.5$ & 91.9 \\
\hline 5 & ipro & 50 & 4 & $>99.5$ & 94.3 \\
\hline 6 & ipro & 40 & 4 & 89.1 & 93.6 \\
\hline 7 & ipro & 60 & 4 & $>99.5$ & 94.6 \\
\hline 8 & ipro & 70 & 4 & $>99.5$ & 91.4 \\
\hline 9 & ipro & 80 & 4 & $>99.5$ & 92.6 \\
\hline 10 & ipro & 50 & 1 & $>99.5$ & 91.3 \\
\hline 11 & ipro & 50 & 2 & $>99.5$ & 92.7 \\
\hline 12 & ipro & 50 & 3 & $>99.5$ & 93.4 \\
\hline 13 & ipro & 50 & 5 & $>99.5$ & 94.6 \\
\hline 14 & ipro & 50 & 6 & $>99.5$ & 95.0 \\
\hline
\end{tabular}

Table 4

Asymmetric hydrogenation of $\beta$-keto esters by Ru/5-BINAP@POPs-1a.

\begin{tabular}{|c|c|c|c|}
\hline Entry & Substrate & Yield b (\%) & $\mathrm{ee}^{\mathrm{b}}(\%)$ \\
\hline 1 & & $>99.5$ & 94.3 \\
\hline 2 & & $>99.5$ & 95.1 \\
\hline 3 & & $>99.5$ & 93.6 \\
\hline 4 & & $>99.5$ & 94.6 \\
\hline 5 & & $>99.5$ & 89.2 \\
\hline 6 & & 85.0 & 92.9 \\
\hline 7 & & $>99.5$ & 90.0 \\
\hline $8^{c}$ & & $>99.5$ & 91.8 \\
\hline $9^{\mathrm{d}}$ & & 92.6 & 91.9 \\
\hline
\end{tabular}

a Reaction conditions: substrates $(1.72 \mathrm{mmol})$, catalyst $(0.00172 \mathrm{mmol}$ $\mathrm{Ru})$, ipro $(2 \mathrm{~mL})$, initial $\mathrm{H}_{2}$ pressure $(4 \mathrm{MPa}), 50^{\circ} \mathrm{C}, 10 \mathrm{~h}$.

${ }^{\mathrm{b}}$ Determined by GC on a Cyclosil-B capillary column.

c Catalyst $(0.00172 \mathrm{mmol} \mathrm{Ru}), \mathrm{S} / \mathrm{C}=4000$.

${ }^{\mathrm{d}}$ Catalyst $(0.0086 \mathrm{mmol} \mathrm{Ru})$, substrates $(43 \mathrm{mmol})$, reaction time $=20$ h.

vents were better selections than the others, and the use of ipro resulted in slightly higher enantioselectivity than the use of methanol (Table 3, entries 1-5). The effect of temperature on the reaction was investigated in the range of $40-80{ }^{\circ} \mathrm{C}$ (Table 3 , entries 5-9). The reaction rate slowed down with decreasing temperature; however, the enantioselectivity was not significantly affected by this factor. In addition, the enantioselectivity improved from $91.3 \%$ to $95.0 \%$ when the $\mathrm{H}_{2}$ pressure in- 
creased from 1 to $6 \mathrm{MPa}$ (Table 3, entries 10-14).

\subsubsection{Expansion of substrate scope}

Next, we examined the scope of asymmetric hydrogenation of $\beta$-keto esters by Ru/5-BINAP@POPs-1 (Table 4). Excellent production yields were obtained with high enantioselectivities. In the hydrogenation of tert-butyl acetoacetate and isobutyl acetoacetate, the catalyst exhibited lower performances than the other substrates (Table 4, entries 5 and 6). Notably, the catalyst demonstrated satisfactory activity at very high molar ratios of the substrate and catalyst $(\mathrm{S} / \mathrm{C}=4000)$ for $10 \mathrm{~h}$ (Table 4 , entry 8 ). When the amount of the reaction substrate was increased to $43 \mathrm{mmol}$, a long reaction time of $20 \mathrm{~h}$ was needed to obtain a satisfactory result (Table 4 , entry 9), which was most likely due to the effect of mass transfer. The uniform distribution of the BINAP ligand in the polymer backbone and abundant pore structures of the catalyst may afford a quasi-homogeneous flexible character to the ligands in the framework while the reaction proceeds [43].

\subsubsection{Reusability of Ru/5-BINAP@POPs-1}

The asymmetric hydrogenation of methyl acetoacetate was selected to evaluate the reusability of Ru/5- BINAP@POPs-1 (Table 5). The catalyst can be reused for at least 6 cycles with complete conversion and high enantioselectivity. We further confirmed the heterogeneous nature of the system using ICP analysis. During the recycling, the amount of Ru species in the filtrate was less than $0.06 \mathrm{ppm}$ for each round of hydrogenation. The morphologies of fresh and used Ru/5-BINAP@POPs-1 were examined using HAADF STEM (Fig. 3). In addition, no obvious $\mathrm{Ru}$ nanoparticles were formed after the sixth run, as evidenced by the EXAFS results (Fig. 2 and Table 1). Note that even with a high $\mathrm{P} / \mathrm{Ru}$ ratio $(\mathrm{P} / \mathrm{Ru}=2)$, the catalyst exhibited high stability during the recycling. The hot filtration test results for the Ru/5-BINAP@POPs-1 in the asymmetric hydrogenation of methyl acetoacetate are presented in Fig. 5. Because the substrate conversion was no more than $15 \%$, the ee value is not listed. The results indicate that when the insoluble catalyst was removed from the hot reaction mixture by filtration, the reaction stopped and no additional products were generated. This finding indicated that the reaction was indeed heterogeneous.

\section{Conclusions}

Two novel vinyl-modified BINAP ligands, 4,4'-divinyl-BINAP and 5,5'-divinyl-BINAP, were successfully synthesized and used as monomers for the preparation of hierarchical porous chiral

\section{Table 5}

Recycling studies for the asymmetric hydrogenation of methyl acetoacetate by Ru/5-BINAP@POPs-1 ${ }^{\text {a }}$.

\begin{tabular}{lrrrrrr}
\hline Run & \multicolumn{1}{c}{1} & \multicolumn{1}{c}{2} & \multicolumn{1}{c}{3} & \multicolumn{1}{c}{4} & \multicolumn{1}{c}{5} & \multicolumn{1}{c}{6} \\
\hline Yield $^{\mathrm{b}}(\%)$ & $>99.5$ & $>99.5$ & $>99.5$ & $>99.5$ & $>99.5$ & $>99.5$ \\
ee $^{\mathrm{b}}(\%)$ & 91.4 & 92.0 & 91.1 & 91.8 & 92.2 & 90.3 \\
\hline
\end{tabular}

a Reaction conditions: substrates $(1.72 \mathrm{mmol})$, catalyst $(0.00172 \mathrm{mmol}$ $\mathrm{Ru}$ ), ipro (2 mL), initial $\mathrm{H}_{2}$ pressure $(4 \mathrm{MPa}), 50^{\circ} \mathrm{C}, 10 \mathrm{~h}$.

b Determined by GC on a Cyclosil-B capillary column.

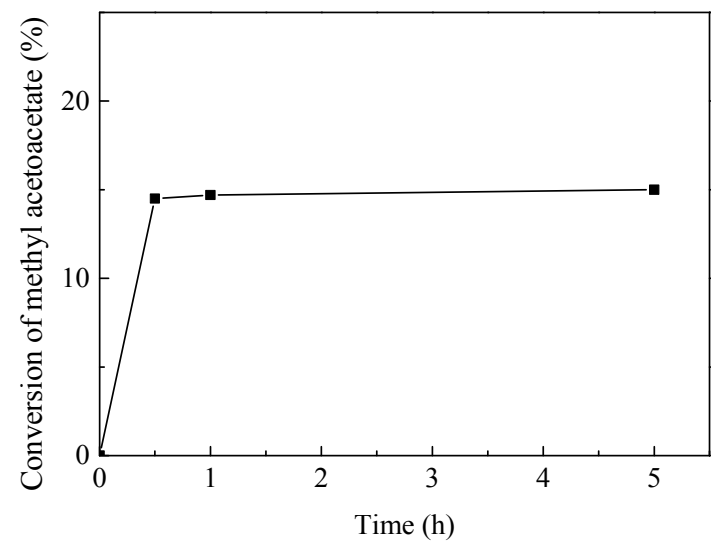

Fig. 5. Hot filtration for the Ru/5-BINAP@POPs-1 catalyst in the asymmetric hydrogenation of methyl acetoacetate. Reaction conditions: methyl acetoacetate (1.72 mmol), catalyst (0.00172 mmol Ru), ipro (2 $\mathrm{mL}$ ), initial $\mathrm{H}_{2}$ pressure (4 MPa), $50^{\circ} \mathrm{C}$.

polymers. The chiral POPs supporting Ru catalysts prepared using two different synthetic routes were systematically investigated to demonstrate their excellent catalytic performance for heterogeneous asymmetric hydrogenation of $\beta$-keto esters. Characterization by NMR and EXAFS confirmed that through copolymerization with DVB, the chiral ligands were incorporated into the polymer backbone by an alkyl linker. The alkyl linker formed by the vinyl groups in the prepared polymers could maintain the quasi-homogeneous flexible character of the BINAP ligand in the polymer backbone [43]. Ru species were firmly coordinated by chiral BINAP ligands fixed on the polymer backbone to prevent leaching during recycling usage. Meanwhile, abundant pore structures and uniformly implanted chiral BINAP ligands in the polymer were favourable for highly efficient chiral inducibility of $\beta$-keto esters on coordinated $\mathrm{Ru}$ sites.

\section{References}

[1] A. G. Hu, H. L. Ngo, W. B. Lin, J. Am. Chem. Soc., 2003, 125, 11490-11491.

[2] C. D. Wu, A. G. Hu, L. Zhang, W. B. Lin, J. Am. Chem. Soc., 2005, 127, 8940-8941.

[3] H. B. Yu, Q. S. Hu, L. Pu, Tetrahedron Lett., 2000, 41, 1681-1685.

[4] Q. H. Fan, C. Y. Ren, C. H. Yeung, W. H. Hu, A. S. C. Chan, J. Am. Chem. Soc., 1999, 121, 7407-7408.

[5] Q. H. Fan, G. H. Liu, G. J. Deng, X. M. Chen, A. S. C. Chan, Tetrahedron Lett., 2001, 42, 9047-9050.

[6] S. Y. Ding, W. Wang, Chem. Soc. Rev., 2013, 42, 548-568.

[7] M. Pilaski, J. Artz, H. U. Islam, A. M. Beale, R. Palkovits, Microporous Mesoporous Mater., 2016, 227, 219-227.

[8] W. Y. Gao, M. Chrzanowski, S. Q. Ma, Chem. Soc. Rev., 2014, 43, 5841-5866.

[9] H. M. El-Kaderi, J. R. Hunt, J. L. Mendoza-Cortes, A. P. Cote, R. E. Taylor, M. O'Keeffe, O. M. Yaghi, Science, 2007, 316, 268-272.

[10] Y. G. Zhang, S. N. Riduan, Chem. Soc. Rev., 2012, 41, 2083-2094.

[11] S. Xu, Z. H. Weng, J. Tan, J. Guo, C. C. Wang, Polym. Chem., 2015, 6, 2892-2899.

[12] S. J. Kraft, G. H. Zhang, D. Childers, F. Dogan, J. T. Miller, S. T. Ngu- 


\title{
Graphical Abstract
}

Chin. J. Catal., 2017, 38: 890-898 doi: 10.1016/S1872-2067(17)62826-2

\section{Chiral BINAP-based hierarchical porous polymers as platforms} for efficient heterogeneous asymmetric catalysis

Tao Wang, Yuan Lyu *, Kai Xiong, Wenlong Wang, Hao Zhang, Zhuangping Zhan, Zheng Jiang, Yunjie Ding *

Dalian Institute of Chemical Physics, Chinese Academy of Sciences; University of Chinese Academy of Sciences;

Xiamen University;

Shanghai Institute of Applied Physics, Chinese Academy of Sciences

Chiral porous organic polymers were obtained via the copolymerization of divinyl-BINAP and divinyl benzene. The heterogeneous catalyst Ru/5-BINAP@POPs-1 exhibited good activity (yield $>99 \%$, ee $=$ $95 \%$ ) and could be reused for 6 runs in the asymmetric hydrogenation of $\beta$-keto esters.
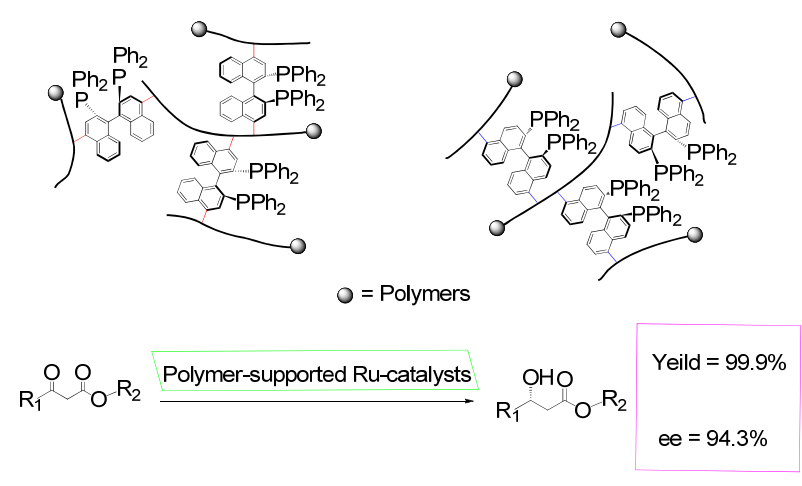

yen, A. S. Hock, Organometallics, 2014, 33, 2517-2522.

[13] W. L. Wang, A. M. Zheng, P. Q. Zhao, C. G. Xia, F. W. Li, ACS Catal., 2014, 4, 321-327.

[14] H. Y. Yang, M. H. Xu, Chin. J. Chem., 2013, 31, 119-122.

[15] Q. Sun, Z. F. Dai, X. J. Meng, F. S. Xiao, Chem. Soc. Rev., 2015, 44, 6018-6034.

[16] P. Kaur, J. T. Hupp, S. B. T. Nguyen, ACS Catal., 2011, 1, 819-835.

[17] T. Ohkuma, H. Takeno, Y. Honda, R. Noyori, Adv. Synth. Catal., 2001, 343, 369-375.

[18] L. Q. Ma, M. M. Wanderley, W. B. Lin, ACS Catal., 2011, 1, 691-697.

[19] W. K. An, M. Y. Han, C. A. Wang, S. M. Yu, Y. Zhang, S. Bai, W. Wang, Chem. Eur. J., 2014, 20, 11019-11028.

[20] D. S. Kundu, J. Schmidt, C. Bleschke, A. Thomas, S. Blechert, Angew. Chem. Int. Ed., 2012, 51, 5456-5459.

[21] J. Q. Dong, Y. Liu, Y. Cui, Chem. Commun., 2014, 50, 14949-14952.

[22] X. Wang, J. Li, S. M. Lu, Y. Liu, C. Li, Chin. J. Catal., 2015, 36, 1170-1174.

[23] Q. Sun, X. J. Meng, X. Liu, X. M. Zhang, Y. Yang, Q. H. Yang, F. S. Xiao, Chem. Commun., 2012, 48, 10505-10507.

[24] Q. Sun, Y. Y. Jin, L. F. Zhu, L. Wang, X. J. Meng, F. S. Xiao, Nano Today, 2013, 8, 342-350.

[25] C. Perego, R. Millini, Chem. Soc. Rev., 2013, 42, 3956-3976.

[26] A. Thomas, Angew. Chem. Int. Ed., 2010, 49, 8328-8344.

[27] Q. Sun, S. Q. Ma, Z. F. Dai, X. J. Meng, F. S. Xiao, J. Mater. Chem. A, 2015, 3, 23871-23875.

[28] X. M. Zhang, Y. P. Zhao, J. Peng, Q. H. Yang, Green Chem., 2015, 17, 1899-1906.

[29] A. Miyashita, A. Yasuda, H. Takaya, K. Toriumi, T. Ito, T. Souchi, R.
Noyori, J. Am. Chem. Soc., 1980, 102, 7932-7934.

[30] R. T. Halle, E. Schulz, M. Spagnol, M. Lemaire, Tetrahedron Lett., 2000, 41, 3323-3326.

[31] E. Framery, B. Andrioletti, M. Lemaire, Tetrahedron, 2010, 21, 1110-1124.

[32] C. Saluzzo, T. Lamouille, F. Le Guyader, M. Lemaire, Tetrahedron: Asymmetry, 2002, 13, 1141-1146.

[33] F. M. Bautista, V. Caballero, J. M. Campelo, D. Luna, J. M. Marinas, A. A. Romero, I. Romero, I. Serrano, A. Llobet, Top. Catal., 2006, 40, 193-205.

[34] T. Wang, Y. Lyu, X. K. Chen, C. Y. Li, M. Jiang, X. G. Song, Y. J. Ding, RSC Adv., 2016, 6, 28447-28450.

[35] Y. X. Liang, Q. Jing, X. Li, L. Shi, K. L. Ding, J. Am. Chem. Soc., 2005, 127, 7694-7695.

[36] J. K. Kassube, H. Wadepohl, L. H. Gade, Adv. Synth. Catal., 2009, 351, 607-616.

[37] P. Y. Wang, X. Liu, J. Yang, Y. Yang, L. Zhang, Q. H. Yang, C. Li, J. Mater. Chem., 2009, 19, 8009-8014.

[38] J. Peng, X. F. Wang, X. M. Zhang, S. Y. Bai, Y. P. Zhao, C. Li, Q. H. Yang, Catal. Sci. Technol., 2015, 5, 666-672.

[39] M. Jiang, L. Yan, X. P. Sun, R. H. Lin, X. G. Song, Z. Jiang, Y. J. Ding, React. Kinet. Mech. Catal., 2015, 116, 223-234.

[40] K. Abdur-Rashid, S. E. Clapham, A. Hadzovic, J. N. Harvey, A. J. Lough, R. H. Morris, J. Am. Chem. Soc., 2002, 124, 15104-15118.

[41] H. L. Ngo, A. G. Hu, W. B. Lin, Chem. Commun., 2003, 1912-1913.

[42] S. Maeda, K. Ohno, J. Am. Chem. Soc., 2008, 130, 17228-17229.

[43] Q. Sun, Z. F. Dai, X. L. Liu, N. Sheng, F. Deng, X. J. Meng, F. S. Xiao, J. Am. Chem. Soc., 2015, 137, 5204-5209.

\section{BINAP嵌入的多孔有机聚合物在多相不对称氢化反应中的作用}

\author{
王 涛 ${ }^{\mathrm{a}, \mathrm{c}}$, 吕 元 $^{\mathrm{a}, \#}$, 熊 凯 ${ }^{\mathrm{d}}$, 汪文龙 ${ }^{\mathrm{a}}$, 张 浩 ${ }^{\mathrm{e}}$, 詹庄平 ${ }^{\mathrm{d}}$, 姜 政, 丁云杰, ${ }^{\mathrm{e},{ }^{*}}$ \\ ${ }^{\mathrm{a}}$ 中国科学院大连化学物理研究所洁净能源国家实验室(筹), 辽宁大连 116023 \\ ${ }^{\mathrm{b}}$ 中国科学院大连化学物理研究所催化基础国家重点实验室, 辽宁大连 116023 \\ ${ }^{\mathrm{c}}$ 中国科学院大学, 北京 100049 \\ $\mathrm{d}$ 厦门大学化学系, 福建厦门361005 \\ e 中国科学院上海应用物理研究所上海同步辐射中心, 上海201204
}

摘要: 手性多孔有机聚合物具有较高的稳定性和催化活性, 广泛用于多相不对称催化中. 目前研究多集中在合成具有微孔 结构的聚合物, 而少有具有多种孔道结构(包含介孔和微孔)的聚合物的报道. 之前我们报道了乙烯基修饰的BINAP配体, 
(S)-5,5'-divinyl-BINAP, 将其与不同单体共聚后得到了一系列具有不同孔结构的有机聚合物. 其负载的 $\mathrm{Rh}$ 基催化剂在苯乙 烯不对称氢甲酰化反应中, 表现出比均相更高的产物对映体选择性. 本文采用不同的溴代步骤, 合成了 (S)-4,4'-divinyl-BINAP配体. 将这两种具有乙烯基官能团的手性配体按相同的摩尔比与二乙烯基苯(DVB)共聚, 得到两种 不同的有机聚合物. 负载 $\left[\mathrm{RuCl}_{2} \text { (benzene) }\right]_{2}$ 后, 分别得到 Ru/4-BINAP@POPs 和Ru/5-BINAP@POPs-1. 采用一锅法合成了 催化剂 $\mathrm{Ru} / 5-\mathrm{BINAP} @ P O P s-2$; 以 $\left[\mathrm{RuCl}_{2} \text { (p-cyme) }\right]_{2}$ 和 $\mathrm{RuCl}_{3}$ 分别合成了 Ru/5-BINAP@POPs-3 和Ru/5-BINAP@POPs-4催化 剂.

$\mathrm{N}_{2}$ 物理吸附结果显示, Ru/4-BINAP@POPs和Ru/5-BINAP@POPs-1催化剂具有相似的孔道结构; 而采用一锅法合成的 Ru/5-BINAP@POPs-2催化剂的介孔孔径较大. 4-BINAP@POPs和5-BINAP@POPs 聚合物的 ${ }^{13}$ C核磁显示, 其均在145, 137 和 $128 \mathrm{ppm}$ 处有明显的吸收峰, 可归结为菜环和苯环上的碳振动峰; 在 $44.0 \mathrm{ppm}$ 处的峰归属为亚甲基上的碳振动峰; ${ }^{31} \mathrm{P}$ 核 磁显示, 在聚合物中P基本没有被氧化.

将所得到的 Ru/POPs 催化剂应用于乙酰乙酸甲酯的多相不对称加氢反应中, Ru/5-BINAP@POPs-1催化剂具有与 Ru/4-BINAP@POPs 更快的反应速率. 在相同反应条件下, 催化剂活性大小为 Ru/5-BINAP@POPs-1 > Ru/5-BINAP@POPs-3 > Ru/5-BINAP@POPs-4 > Ru/5-BINAP@POPs-2. 另外Ru/5-BINAP@POPs-1催化剂对 $\beta$-酮酸酯有着 较好的底物适应性, 且在釜式反应中可循环使用6次而活性基本不变.

分析发现, 使用前后的催化剂均没有明显的 $\mathrm{Ru}-\mathrm{Ru}$ 键的存在. 表明 $\mathrm{Ru}$ 金属高度分散于催化剂上, 且具有较高的稳定性, 金属不易聚集, 这也是其具有高活性和稳定性的原因.

关键词: (S)-4,4'-二乙烯基-BINAP; (S)-5,5' -二乙烯基-BINAP; 聚合物负载钉催化剂; 多相不对称加氢; $\beta$-酮酸酯

收稿日期: 2017-02-22. 接受日期: 2017-03-23. 出版日期: 2017-05-05.

*通讯联系人. 电话/传真: (0411)84379143; 电子信箱: dyj@dicp.ac.cn

\#通讯联系人. 电话: (0411)84379601; 传真: (0411)84379143; 电子信箱: luyuan@dicp.ac.cn

基金来源: 中国科学院战略先导研究计划(XDB17020400).

本文的英文电子版由Elsevier出版社在ScienceDirect上出版(http://www.sciencedirect.com/science/journal/18722067). 